\title{
Quality of Life of Hemodialysis Elderly Patients at Assiut City
}

ISSN: 2578-0093

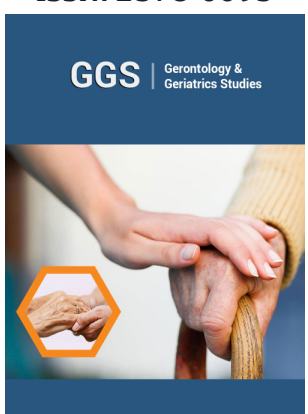

*Corresponding author: Hassan $\mathrm{AB}$, Nursing Specialist at Technical Nursing Institute, Egypt

Submission: 毕January 06, 2020

Published: 淟January 28, 2020

Volume 5 - Issue 4

How to cite this article: Hassan $\mathrm{A}$, Ibrahem H, Sharkawy S, Abo-Zaid H. Quality of Life of Hemodialysis Elderly Patients at Assiut City. Gerontol \& Geriatric stud.5(4). GGS.000619.2020.

DOI: $10.31031 /$ GGS.2020.05.000619

Copyright@ Hassan AB, This article is distributed under the terms of the Creative Commons Attribution 4.0 International License, which permits unrestricted use and redistribution provided that the original author and source are credited.

\author{
Hassan $\mathrm{AB}^{* 1}$, Ibrahem $\mathrm{HDF}^{2}$, Sharkawy $\mathrm{SA}^{3}$, Abo-Zaid HA ${ }^{4}$ \\ ${ }^{1}$ Nursing Specialist at Technical Nursing Institute, Egypt \\ ${ }^{2}$ Professor of Community Health Nursing, Egypt \\ ${ }^{3}$ Assistant Professor of Community Health Nursing, Egypt \\ ${ }^{4}$ Lecturer of Gerontological Nursing, Egypt
}

\begin{abstract}
Background: All stages of CKD are associated with increased risks of premature mortality and/or decreased quality of life.
\end{abstract}

Aims of the study: To assess quality of life for hemodialysis elderly patients at Assiut city.

Subjects and method: descriptive design was carried out for hemodialysis elderly patients (83) within all hemodialysis units at Assiut city. Structured interview questionnaire developed by the researchers was used in the study, it was structured into two parts: Part 1): It was included personal characteristics of the elderly, such as name, age, marital status. etc., Part (2): Quality of life index scale, Dialysis Version-III, Arabic Version [1].

Results: It was noticed that $71.1 \%$ of the studied elderly hemodialysis patients' age ranged from $65-75$ years old, while only $4.8 \%$ of them were more than 85 years old $90.4 \%$ of hemodialysis elderly had mild to moderate QOL.

Conclusion: It was concluded that less than on tenth of the studied hemodialysis elderly had high quality of life.

Recommendation: Enhance health care services level for elderly to eliminate complications and improve quality of life, develop specific transportation supportive system for retired elderly to improve quality of life.

Keywords: Elderly; Hemodialysis; Quality of life

\section{Introduction}

During the last century, human lifespan has increased substantially resulting in a substantial increase of elderly people over the next two decades. Individuals aged 65 years or more represented $12.8 \%$ of US population in 2008. By 2030, the number of elderly people is expected to be 71 million, accounting for $21 \%$ of US population (Bolignano, et al, 2014). One in 10 people worldwide have kidney disease, according to the first detailed global report on care delivery for kidney disease, although high-income countries have the highest costs for dialysis and kidney transplantation, fewer than one (29\%) in three high-income countries consider chronic kidney disease a priority compared with almost two (59\%) in three low-income countries (Marcia , 2017). Acute kidney injury (AKI) is a syndrome characterized by a rapid (hours to days) deterioration of kidney function. It is often diagnosed in the context of other acute illnesses and is particularly common in critically ill patients. The clinical consequences of AKI include the accumulation of waste products, electrolytes, and fluid, but also less obvious effects, including reduced immunity and dysfunction of non-renal organs (organ crosstalk) (Singbartl \& Joannidis, 2015). Chronic kidney disease (CKD) is a global health burden with a high economic cost to health systems and is an independent risk factor for cardiovascular disease (CVD). All stages of CKD are associated with increased risks of cardiovascular morbidity, premature mortality, and/or decreased quality of life [2].

\section{Study rational}

Patients in the final stage of the CKD have a worse quality of life (QOL) in comparison to the general population of the same age. The treatment for CKD patients aims should not be only 
longevity, but also the strengthening of QOL, since plain survival it is not enough, it is necessary to live well [3]. In a study of prevalence of end stage renal disease in As suit Governorate, Upper Egypt, A cross-sectional multi centric study was carried out with 1109 at As suit Governorate patients in 13 hemodialysis units found that more than $25 \%$ of End Stage Renal Disease patients are $>50$ years old age [4]. Gerontological nurses work with healthy older adults in their communities, acutely. The role of gerontological nurses has a significant role to play in the care of older people. They provide focused health screening, counseling, crisis intervention, and comprehensive care to this population. They serve as important advocates in directing appropriate utilization of resources and making referrals that promote continuity of care geared to the needs of older adults. Provide essential educational services to older clients, their families, and other nursing and health care professionals involved in their care (Mauk, 2014).

\section{Research questions}

Do the hemodialysis Elderly patients have low quality of life?

Do the hemodialysis Elderly patients have low satisfaction toward different life aspects?

Do the hemodialysis Elderly patients have low importance in according to different life aspects?

\section{Aim of the study}

To assess quality of life of hemodialysis elderly patients in Assiut city.

\section{Subjects and Method}

\section{Research design}

Descriptive research design was carried out in the present study.

\section{Setting}

The study carried out for hemodialysis elderly patients within all hemodialysis units at Assiut city; it was included: Assiut University Hospital's hemodialysis unit, Health Insurance Hospital's hemodialysis unit, Al- Iman General Hospital's hemodialysis unit, Assiut General Hospital's hemodialysis unit, and Assiut Fever Hospital's hemodialysis unit.

\section{Subjects}

The target population of the study are included all elderly ( $\geq 65$ years) with end stage of renal disease and treated with hemodialysis, which included 83 elderly patients from the previous setting.

\section{Sampling technique}

Convenient sample are used in this study. The patients are selected by total coverage technique.

\section{Tools of the study}

Structured interview questionnaire developed by the researchers for data collection based on review of related literature. It was structured into two parts:

Part (1): It was included personal characteristics of the elderly, such as name, educational status, age, marital status ...etc.

Part (2): Quality of life index scale, Dialysis Version-III, Arabic Version (Halabi, 2004), that composed of two domains:

a) Part 1: Likert Scale statement ranged from (1=very dissatisfied to $6=$ very satisfied) that describe how the patient satisfied with that area of his life it includes 34 statement.

b) Part no 2: Likert Scale statement ranged from (1=very unimportant to $6=$ very important) that describe how important that area of the elderly patient's life it includes 34 statement.

The necessary modification in the scale was done to be suitable to the study conditions as following:

a) Part 1: Likert Scale statement ranged from (1=dissatisfied, $2=$ =moderate satisfied and $3=$ satisfied) that describe how the patient satisfied with that area of his life it includes 29 statement.

b) Part 2: Likert Scale statement ranged from (1=unimportant, $2=$ moderate important and $3=$ important) that describe how important that area of the elderly patient's life it includes 30 statement.

Total scoring system for Hemodialysis Patient's Quality of Life scale: $<60 \%$ indicate low quality of life, from $60 \%$ to less than $85 \%$ indicate mild to moderate quality of life, and $85 \%$ and more indicate high quality of life [1].

\section{Validity}

The tool was reviewed by 5 experts in the field of nursing science who reviewed the instrument for clarity, relevance, understanding, and applicability.

\section{Reliability}

The Cronbach's alpha coefficient for the instrument was 0.94 with a test-retest reliability of 0.94 .

\section{Methodology}

\section{Administrative phase}

An official letter approval was obtained from the Dean of the Faculty of Nursing Assiut University to the previous mentioned setting and an official letter approval was obtained from each mentioned setting which includes a permission to carry out the study in the selected areas.

\section{Ethical considerations}

The research proposal was approved from ethical committee in the faculty of nursing, there is no risk for the study' subjects during application of the research, participants were advised of their rights to withdraw from the study at any point, participants were coded for data entry so their names couldn't be identified, participant agreement for voluntary participation was obtained and the nature of the study was explained, confidentiality anonymity was assured. 


\section{Pilot study}

Pilot study was carried out before starting data collection on 10 percent from the elderly hemodialysis patients. It aimed to test the clarity of the tools and to estimate the required time to fill the questionnaire, and the pilot study was included in the study.

\section{Field work}

The researcher started to collect data from first of September 2016, until the end of June 2017. After obtaining approval for conducting the study, the researcher referred to the dialysis unit in every previous mentioned setting and selected all the patients who met the inclusion criteria via interviews and review of medical records.

\section{Statistical analysis and scoring system}

The obtained data reviewed, prepared for computer entry, coded, analyzed, and tabulated. The data were tested for normality using the Anderson-Darling test and for homogeneity variances prior to further statistical analysis. Categorical variables were described by number and percent, where continuous variables described by mean and standard deviation (Mean, SD). Chi-square test used to compare between categorical variables where compare between continuous variables, $\mathrm{p}<0.05$ was considered statistically significant. All analyses were performed with the IBM SPSS 20.0 software.

The results of the present study are representing the relation between hemodialysis elderly patients' quality of life and their family caregivers' burden. Table 1 shows the personal characteristics of the studied elderly hemodialysis patients, it was noticed that $71.1 \%$ of the studied elderly hemodialysis patients' age ranged from $65-75$ years old, while only $4.8 \%$ of them were more than 85 years old. The table revealed that $31.3 \%$ of the studied elderly hemodialysis patients had the disease for 5-10 years ago, in which $53 \%$ of them had the disease since less than 5 years. Also $86.7 \%$ of elderly where live with their family care givers.

Table 1: Personal characteristics of the studied hemodialysis elderly patients, at as suit city' hospital, 2017 (no. $=83$ ).

\begin{tabular}{|c|c|c|}
\hline Items & No & $\mathbf{\%} / \mathbf{1 0 0}$ \\
\hline Age & & \\
\hline $65-<75$ years & 59 & 71.1 \\
\hline $75-<84$ years & 20 & 24.1 \\
\hline$\geq 85$ years & 4 & 4.8 \\
\hline Gender & & \\
\hline Male & 52 & 62.7 \\
\hline Female & 31 & 37.3 \\
\hline Social status & 1 & \\
\hline Single & 48 & 57.8 \\
\hline Married & 3 & 3.6 \\
\hline Divorced & & \\
\hline
\end{tabular}

\begin{tabular}{|c|c|c|}
\hline Widowed & 31 & 37.3 \\
\hline Level of Education & & \\
\hline Illiterate & 22 & 26.5 \\
\hline Reads and writes & 6 & 7.2 \\
\hline Basic education & 22 & 26.5 \\
\hline Secondary education & 5 & 6 \\
\hline University & 28 & 33.7 \\
\hline Residence & & \\
\hline Rural & 37 & 44.6 \\
\hline Urban & 46 & 55.4 \\
\hline The duration of the disease & & \\
\hline less than 5 years & 44 & 31.3 \\
\hline 5-10 years & 26 & 15.7 \\
\hline more than 10 years & 13 & \\
\hline Where the elderly live & & 13.3 \\
\hline Live alone & 11 & 86.7 \\
\hline Live with family & 72 & \\
\hline
\end{tabular}

Table 2 illustrate that $9.6 \%, 37.3 \%$ \& $53 \%$ of the studied elderly shown high satisfaction, were not satisfied \& mild to moderate satisfied with their life, respectively. As Table 3 shows 15.7\%, 83.1 have high importance toward their life' aspects and mild to moderate importance, respectively. Figure 1 illustrates the total quality of life scale for hemodialysis Elderly patients, in which $3.6 \%$ of them had low quality of life $\& 90.4 \%$ of them had mild to moderate quality of life, respectively. Table 3 illustrate the relationship between total quality of life and personal characteristics of studied hemodialysis elderly patient, in which $65.0 \%, 56.6 \%, 53.0 \%$ of elderly that 65-74 years, males \& married, had mild quality of life respectively.

Table 2: Satisfaction domain of quality of life, for the studied elderly patients, at as suit city' hospitals, 2017(no $=83)$.

\begin{tabular}{|c|c|c|}
\hline \multirow{2}{*}{ Quality of Life (Satisfaction Domain) } & \multicolumn{2}{|c|}{ Pretest } \\
\cline { 2 - 3 } & No & $\%$ \\
\hline Not satisfied & 31 & 37.3 \\
\hline Mild to moderate satisfaction & 44 & 53 \\
\hline high satisfaction & 8 & 9.6 \\
\hline
\end{tabular}

Table 3: Importance domain of quality of life, for the studied elderly patients, at as suit city' hospitals, 2017 (no $=83)$.

\begin{tabular}{|c|c|c|}
\hline \multirow{2}{*}{ Quality of Life (Satisfaction Domain) } & \multicolumn{2}{|c|}{ Pretest } \\
\cline { 2 - 3 } & No & \% \\
\hline Not satisfied & 31 & 37.3 \\
\hline Mild to moderate satisfaction & 44 & 53 \\
\hline high satisfaction & 8 & 9.6 \\
\hline
\end{tabular}


Total Quality of life of the studied hemodialysis elderly patients at Assuit city

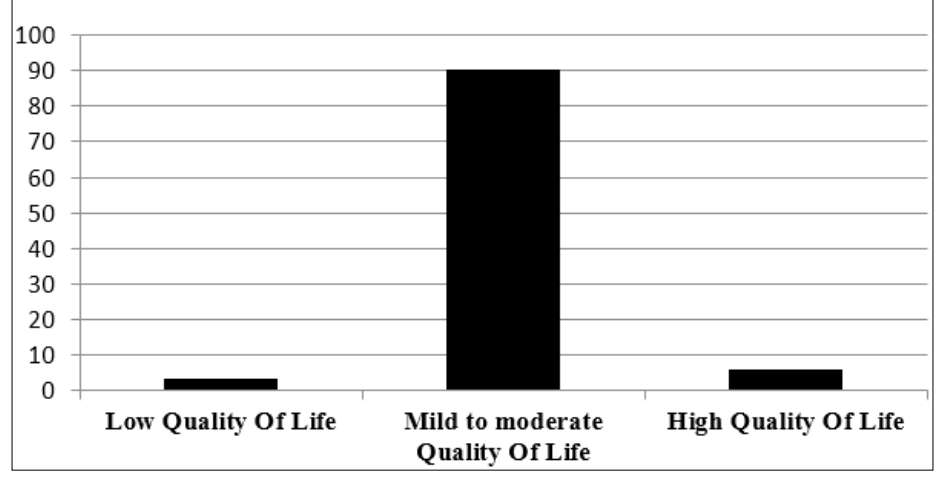

Figure 1: Total quality of life scale among studied elderly, at As suit city' hospital, 2017 (No. = 83).

\section{Discussion}

Chronic Kidney Disease (CKD) can be defined by a renal parenchymal injury (with normal kidney function) and/or by impaired renal function that persists for a period of three months or longer. CKD has gained increased attention from the international scientific community as a high prevalence of it has been reported in studies (Salvador and Magdalena, 2015). Regarding personal characteristics of the studied hemodialysis elderly, the finding of the present study revealed that about two third of them were male, in which about one third were female, and more than half of them were married, The predominance of data in humans suggests that the course of non-diabetic kidney disease is more aggressive in men than women. Male gender is arguably also a risk factor for progression of diabetic nephropathy [5].

Also the results of [6] who conducted a study in Preto Da University about (factors associated with the quality of life of patients undergoing hemodialysis) reported that about two third of the studied elderly were males, and about one third were female, in which more than half were married. While Havva [7] who conducted a study about Determining Quality of Life and Sleep in Hemodialysis Patients in Turkey university, who showed that most of the studied elderly were females.

The present study shows that more than two third of the studied elderly were $65-<75$ years old. It may relate to the life span in Egypt, 2016 is 71.48 years old [8]. This agreed with Melo et al. [9] who conduct a study in Brazil university about (health-related quality of life in elderly chronic kidney disease patients undergoing hemodialysis) who reported that more than two third of the studied elderly had the same age such as the present study. The finding of the present study revealed that most of the studied elderly were live with family. It related to the extended family tradition that preserved till now in Upper Egypt. These results on the contrary with study conducted by Melo et al. [9] showed that most of the studied elderly were life alone in their own places.

The perception of quality of Life by patients with end-stage renal disease is an important measure of patient outcome. Patients on hemodialysis have a significant level of disturbance in their quality of Life [10]. In the present study revealed that most of the studied elderly' quality of Life were determined to be mild to moderate. This finding is consistent with Havva [7] who revealed that the studied elderly had a mild to moderate quality of Life. In the present study, the variable of educational level had effect on the total quality of life. In which, a very low percent of the studied hemodialysis elderly that had high educational level had high quality of life. This finding was in the same line with findings of studies that conducted by Manns et al. [11] about quality of life in patients treated with hemodialysis or peritoneal dialysis: What are the important determinants who reported that higher educated studied elderly showed higher quality of life.

Concerning to the duration of dialysis the patient how had dialysis duration from 5-10 years only less than five percent of them had high quality of life. This was agreed with Assal et al. [12] who conducted a study about health-related quality of life among Egyptian patients on hemodialysis, in Egypt Found that there was a negative correlation between quality of life of the studied elderly and duration on dialysis. However, other studies were disagreed with our finding such as (Adel \& Abdul Manaf, 2012) who reported that there was no relation between dialysis duration and quality of life level [13].

\section{Conclusion}

Based on the results of the present study, it can be concluded that:

More than two half of the studied elderly showed mild to moderate satisfaction toward their life, The results illustrate that only more than one tenth of the studied elderly showed high importance toward life aspects of their life \& less than on tenth of them had high quality of life.

\section{Recommendation}

Enhance health care services level for retired elderly to eliminate complications and improve quality of life, provide easy access transportation for elderly to improve quality of life. 


\section{References}

1. Halabi JO (2006) Psychometric properties of the Arabic version of quality of life index. J Adv Nurs 55(5): 604-610.

2. Nathan RH, Fatoba ST, Oke JL, Hirst JA, Callaghan AC, et al. (2016) Global prevalence of chronic kidney disease-a systematic review and metaanalysis. PLoS One 11(7): e0158765.

3. Pereira RMP, Batista MA, Meira AS, Oliveira MP, Kusumota L (2017) Quality of life of elderly people with chronic kidney disease in conservative treatment. Rev Bras Enferm 70(4): 851-859.

4. Abbasi A, Asayesh H, Rahmani H, Shariati A, Hosseini SA, et al. (2011) The burden on cargivers from hemodialysis patients and related factors. Journal of Research Development in Nursing and Midwifery 8(1): 26-33.

5. Neugarten J, Golestaneh L (2013) Gender and the prevalence and progression of renal disease. Adv Chronic Kidney Dis 20(5): 390-395.

6. Gesualdo GD, Menezes ALC, Rusa SG, Napoleão AA, Rosely M, et al (2017) Factors associated with the quality of life of patients undergoing hemodialysis. Texto Contexto Enferm 26(2): e05600015.
7. Havva T (2009) Determining quality of life and sleep in hemodialysis patients. Dialysis \& Transplantation Journal 38(6): 210-215.

8. CAPMUS (2016) Prevalence of Egyptian elderly profile.

9. Melo GAA, Renan AS, Francisco GF, Sarah LP, Leonardo AS, et al. (2016) Health-related quality of life in elderly chronic kidney disease patients undergoing hemodialysis. International Medical society Journal 9(141): $1-10$.

10. National Kidney Foundation (2017) KDOQI clinical practice guidelines and clinical practice recommendations for anemia in chronic kidney disease. Am J Kidney Dis 47:1-145.

11. Manns B, Johnson JA, Taub K, Mortis G, Ghali WA, et al. (2003) Quality of life in patients treated with hemodialysis or peritoneal dialysis: What are the important determinants? Clin Nephrol 60(5): 341-351.

12. Assal H, Emam H, Ghaffar NAE (2006) Health related quality of life among Egyptian patients on hemodialysis. J Med Sci 6(3): 314-320.

13. Frellick M (2017) One in 10 people worldwide have chronic kidney disease. Medscape.

For possible submissions Click below: 